\title{
BASES FREUDIANAS PARA UMA ABORDAGEM DISCURSIVA DO AFETO
}

\author{
FREUDIAN BASES FOR A DISCURSIVE APPROACH OF AFFECTION \\ BASES FREUDIANAS DE UN ENFOQUE DISCURSIVO DEL AFECTO
}

\author{
Tiago Ravanello* \\ Waldir Beividas ${ }^{* *}$ \\ Flávia Milanez de Farias ${ }^{* *}$
}

\begin{abstract}
RESUMO
Neste artigo, nós nos dedicaremos a interceptar mais diretamente a relação entre afeto e linguagem nas bases do campo freudiano. Buscaremos delinear características inerentes à consideração destes e sua mútua implicação, e elencar pontos de apoio para a questão da discursivização do afeto em Freud. No entanto nosso objetivo principal não é a delimitação de uma abordagem freudiana do afeto, mas destacar bases que apontem a pertinência da retomada do conceito de afeto no interior de uma discussão rigorosa sobre a linguagem e apresentar brevemente alguns obstáculos que poderiam impossibilitar o diálogo entre a psicanálise e as teorias da linguagem. Para tanto, faremos um breve trajeto para delimitar duas possíveis maneiras de abordagem para o conceito de afeto, a "quantitativa" e a "metafórica", com base no estudo de obras freudianas e seus críticos.
\end{abstract}

Palavras-chave: Afeto. Psicanálise. Linguagem.

\begin{abstract}
In this paper, we mean to intercept more directly the rapport between affect and language in the bases of the Freudian field. We aim at outlining characteristics inherent to their consideration and their mutual involvement, as well as listing points bearing the matter of discoursivization of affection in Freud's work. However, our main objective is not to determine a Freudian approach of affection, but to highlight bases that point out the relevance of taking over the concept of affection from within a rigorous debate about the language, presenting shortly some obstacles that could preclude a dialogue between psychoanalysis and the language theories. With that in mind, we shall outline a short path so as to determine two possible ways to approach
\end{abstract}

\footnotetext{
Texto recebido em 12 de junho de 2015 e aprovado para publicação em 15 de setembro de 2016.

Professor doutor adjunto no Centro de Ciências Humanas e Sociais da Universidade Federal de Mato Grosso do Sul (UFMS). E-mail: tiagoravanello@yahoo.com.br.

** Professor doutor no Departamento de Linguística (Graduação e Pós-Graduação) da Universidade de São Paulo (USP). E-mail: waldirbeividas@gmail.com.

*** Mestra em Psicologia pelo Programa de Pós-Graduação em Psicologia da UFMS. E-mail: fla-psi@hotmail.com.
} 
the concept of affection, a "quantitative" and a "metaphorical one", based on the study of Freud's works and his critics.

Keywords: Affect. Psychoanalysis. Language.

\section{RESUMEN}

En este artículo nos dedicaremos a captar de forma más directa la relación entre el afecto y el lenguaje en las bases del campo freudiano. Intentaremos definir las características inherentes a la consideración de éstos y su mutua implicación y enumerar puntos de apoyo a la cuestión de la discursivización del afecto para Freud. Sin embargo, nuestro objetivo principal no es la delimitación de un enfoque freudiano del afecto, sino destacar bases que señalen la pertinencia de recuperar el novada del concepto de afecto dentro de un debate riguroso sobre el lenguaje, y presentar brevemente algunos obstáculos que podrían impedir el diálogo entre el psicoanálisis y las teorías del lenguaje. Para eso, vamos a hacer un breve trayecto para delimitar dos posibles maneras de abordar el concepto de afecto, el "cuantitativo" y el "metafórico", a partir del estudio de las obras de Freud y sus críticos.

Palabras clave: Afecto. Psicoanálisis. Lenguaje.

\section{INTRODUÇÃO}

0 afeto acaba por se tornar o fiel da balança epistemológica quanto ao freudismo: segundo a leitura de pesquisadores que aderem à "intenção naturalista”, explicitada por Freud $(1895 / 1996)^{1}$ na primeira página de seu Projeto para uma Psicologia Cientifica ${ }^{2}$, e que assumem o pressuposto de identificação entre as ordens físico e mental, o afeto é considerado como o principal elemento de uma hipótese quantitativa que prova a persistência do texto de 1895 na elaboração das principais teses psicanalíticas. Já segundo a apresentação de autores que lançam mão de outras referências epistemológicas (principalmente aquelas ligadas a matrizes de pensamento discursivas), o conceito de afeto pode ser visto justamente como a passagem da predominância da abordagem quantitativa em Freud para a possibilidade de superação da intenção do Projeto por meio da preponderância dada à linguagem na elaboração do edifício psicanalítico. Roudinesco (2000) apresenta, de uma maneira bastante instrutiva, a forma alternante com que essas duas posturas podem ser evidenciadas:

Para os freudianos clássicos, esse manuscrito representa apenas uma etapa na construção de uma verdadeira teoria do inconsciente, libertada de qualquer substrato cerebral. E,

\footnotetext{
1 A primeira data indica o ano de publicação original da obra, e a segunda, a edição consultada pelo autor e só será pontuada na primeira citação da obra no texto. Nas seguintes, será registrada apenas a data de publicação original.

2 O nome do texto será abreviado nas referências posteriores.
} 
se Freud rejeitou o texto, a ponto de nunca mais pedi-lo de volta a seu amigo Wilhelm Fliess, isso decerto significa que, mesmo abandonando-a, ele sempre foi atormentado pela tentação de uma "naturalização" da ciência do psiquismo. Por isso, o Projeto ficou como uma espécie de fantasma invisível, atravessando sem cessar todos os escritos freudianos (Roudinesco, 2000, p. 64, grifo nosso).

De um lado, o rechaço do Projeto no caminho para uma teoria do inconsciente independente do aporte neuronal. De outro, a tentação epistemológica frequente de infletir seus conceitos para a verve naturalista. $\mathrm{O}$ conceito de afeto é resultado do conflito entre essas possibilidades de abordagem.

\section{ABORDAGEM QUANTITATIVA DO AFETO}

Os modos pelos quais uma leitura do conceito de afeto (bem como de outros conceitos do ponto de vista econômico da teoria freudiana) que privilegie seus aspectos quantitativos tem levado uma série de autores a traçar linhas de união, seja em relação ao passado, entre Freud e correntes naturalistas e organicistas de pesquisa, seja visando ao futuro, entre a teoria psicanalítica e projetos biologizantes e neurocientíficos. Na primeira linha, a teoria freudiana nada mais seria do que o desenvolvimento e aplicação de hipóteses originadas no interior de concepções que priorizavam o orgânico na determinação de fenômenos causais (como no caso do naturalismo e do fisicalismo). Já conforme a segunda linha, os pressupostos da psicanálise erigida por Freud estariam de tal modo vinculados a estruturas e processos neuronais que as chaves para sua compreensão e aplicabilidade encontrar-se-iam invariavelmente nas mãos das chamadas "novas ciências da mente" (cognitivas e neurocientíficas), que, segundo a crítica de Birman (2007), "Tendem a forçar uma abordagem do funcionamento psíquico enquanto redutível ao funcionamento cerebral e os modelos de funcionamento bioquímico suposto a ele" (pp. 181-182).

Em ambos os casos, o objetivo acaba sendo o mesmo: decretar a submissão da psicanálise ao registro de determinações de cunho natural e biológico. A diferença está em que, seguindo a primeira linha argumentativa, tal procedimento é almejado em termos de um "reducionismo epistemológico", através da defesa da continuidade dos planos conceituais, como apontamos na leitura de autores como

Barros (1998a, 1998b), Caropreso e Simanke (2006, 2008), Gabbi Júnior (2003), Gomes (2005), Grünbaum (1993, 1998), Rossi (2005), Sulloway (1998), entre outros. Já em relação à segunda, trata-se mais de uma tentativa de "reducionismo metodológico" pela defesa do que deveria vir a ser o desenrolar das concepções teóricas futuras bem como da continuidade dos níveis de aporte 
entre o somático e o psíquico. Essa postura, conforme nos foi possível apontar, é defendida por Andrade (2003), Changeux (1998), Changeux et al (1991), Damasio (2000), Dennett (1997), para citar somente alguns exemplos.

Conforme Assoun (1996) nos propõe, a noção de um "processo psicofisiológico" capaz de portar em si um elemento representacional e outro afetivo é tributária dos Princípios de Psicologia fisiológica, de Wundt (Assoun, 1996, p. 152). Nessa obra, Freud teria encontrado então o modelo conceitual que lhe fora útil nas primeiras abordagens do conceito de afeto. Da mesma forma, é também na matriz fisicalista que Plastino (2001) considera que a "intuição fundamental" de Freud foi gerada, em se tratando do afeto, priorizando o seu caráter quantitativo por meio da concepção de energia de investimento (Plastino, 2001, pp. 170171). Com efeito, se a vinculação com o modelo naturalista foi influente a ponto de prover um modelo inicial para o conceito de afeto e, ao mesmo tempo, se a proximidade de Freud com as teorias fisicalistas permitiu a doção do aspecto quantitativo na compreensão dos fenômenos ligados ao psiquismo, o resultado final desse preâmbulo epistemológico deve ser compreendido não somente como a concepção quantitativa do afeto, mas também na sua tensão com o aspecto representativo. As possibilidades que cada texto freudiano abrirá para dissociar ou aproximar a intensidade (aqui representada como quantidade) do sentido (como representação) serão de extrema importância para a compreensão da abordagem do afeto em questão.

As bases de uma concepção de cunho energético do afeto podem ser facilmente encontradas nos textos iniciais de Freud (1893a/1996; 1895) bem como por várias vezes retomadas ao longo de sua obra. Assim, em Estudos sobre a histeria Freud (1893b/1996), irá assentar na "reação energética" (p. 43) e na capacidade de descarga de afetos (p. 44) as condições de resiliência perante os fenômenos histéricos. Novamente o trauma deve ser visto como resultado da impossibilidade de escoar a quantidade, ou seja, de seu represamento incidindo sobre a representação traumática. Fala-se, então, de afeto estrangulado (p. 52) como de um rio barrado em seu curso. Porém, ainda mais importante, e ao que devemos nos ater, é justamente um dos destinos possíveis a essa quantidade represada: o desvio desde seu traço mnêmico em direção a uma "inervação somática” (p. 298). Um adepto de um suposto naturalismo freudiano nos indagaria: como não ver, nessa abordagem do afeto, um recurso para a assimilação dos fenômenos mentais e psicopatológicos ao seu suposto aporte físico? Como estamos evidenciando nesses comentários, é justamente sobre pontos como este que estratégias de abarcamento da psicanálise às neurociências acabam por se dar. Vejamos o seguinte excerto desse mesmo texto sobre a histeria: 
Como explicamos na "Comunicação Preliminar" que aparece no início deste volume, consideramos os sintomas histéricos como efeitos e resíduos de excitações que atuaram sobre o sistema nervoso como traumas. Não há permanência de resíduos dessa natureza quando a excitação original é descarregada por ab-reação ou pela atividade do pensamento. Não é mais possível, a esta altura, evitar a introdução da ideia de quantidades (ainda que não mensuráveis). Devemos considerar o processo como se uma soma de excitação, atuando sobre o sistema nervoso, se transformasse em sintomas crônicos, na medida em que não fosse empregada em ações externas na proporção de sua quantidade (Freud, 1893b, p. 116).

Aqui, como Freud (1893b) tende a conduzir a discussão, a noção de quantidade subjacente à abordagem ora empregada para os fenômenos ditos afetivos deve ser vista como uma inferência necessária, contingente ao material estudado, em suma, como uma "evidência" de pesquisa. Entretanto devemos ressaltar que a evidência que Freud alega encontrar, do modo como é descrita, está inteiramente subsumida à máxima de que "os histéricos sofrem principalmente de reminiscências" (p. 43), ou seja, que seus sintomas têm uma etiologia psíquica. Toda a suposição que então se segue (da atuação da soma de excitações no sistema nervoso, da ab-reação, da quantidade) deve-se muito mais ao esquema epistemológico então empregado em suas pesquisas do que necessariamente à constatação de um dado observacional forte.

Conforme as concepções referentes aos procedimentos avançam no percurso freudiano, a tendência mais visível sobre o tema é justamente a nuance quanto ao rigor na utilização do recurso explicativo diretamente vinculado à noção de quantidade. Simultaneamente a isso, o ponto de vista econômico vai paulatinamente se concretizando ao redor dessas noções, estabilizando os conceitos de quota de afeto e de soma de excitação, em detrimento do termo quantidade apresentado pura e simplesmente. Abre-se, assim, uma margem conceitual a partir da compreensão dos procedimentos que estes conceitos envolvem, ou seja, a quantidade vai deixando de apresentar-se numa espécie de estado bruto e passa a formas mais nuançadas de definição.

Uma forma interessante de observar esse movimento é recorrer à releitura de Freud sobre o tema. Vejamos, por exemplo, o que em 1923, no verbete sobre psicanálise, o autor nos fala a respeito dos Estudos sobre histeria:

Desde o início, o fator do afeto foi trazido para o primeiro plano: os sintomas histéricos [...] surgiam quando um processo mental com pesada carga emocional era de alguma maneira impedido de nivelar-se ao longo do caminho normal que conduz à consciência e ao movimento (Freud, 1923, p. 254, grifo do autor).

Ressaltemos aqui algo digno de nota: a inclusão da expressão "carga emocional" para a retomada do texto sobre a histeria. Trata-se aqui, claramente, 
de uma releitura atravessada pelos temas desenvolvidos durante exatos 30 anos de pesquisa sobre os fundamentos da psicanálise.

Caso semelhante pode ser encontrado em Um estudo autobiográfico, Freud (1925/1996), no qual retoma a importância da ênfase dada pelo então novíssimo método psicanalítico "à significação da vida das emoções" antes de mencionar a introdução dos fatores dinâmicos e econômicos do afeto (Freud, 1925, p. 28). Conflito de matrizes de pensamento? Não necessariamente, ao menos segundo o ponto de vista freudiano. A significação na origem dos sintomas histéricos quando colocada lado a lado com a dinâmica do "represamento do afeto" e com a hipótese econômica reduzida à "transformação de uma quantidade de energia" nos permite delimitar o quanto tais linhas de abordagem apresentavam-se ao espírito de pesquisa freudiano como reversos da mesma moeda. Entretanto, como o próprio autor aponta, a "teoria fisiológica" de Breuer cedeu lugar para a visada sobre os conflitos de forças a partir da "atuação de intençôes e propósitos" (Freud, 1925, p. 29). Assim, o uso do vocabulário quantitativo vai progressivamente entrando em conformidade com a abordagem clínica e, consequentemente, com termos de caráter discursivo.

A modificação de postura quanto ao tema é, de certa forma, ratificada pelo próprio autor em Minhas teses sobre o papel da sexualidade na etiologia das neuroses (Freud, 1906/1996). Aqui, ele aponta sutilmente a passagem do entendimento fechado do surgimento da histeria no "afeto estrangulado" e sua subsequente transposição em inervação somática (p. 259) para o atravessamento no processo de formação dos sintomas pelas "fantasias" e "lembranças infantis", no que seria a transição da localização do fator etiológico dos "traumas sexuais infantis" para o "infantilismo da sexualidade" (p. 261). A temática da sexualidade e sua relação com a etiologia das neuroses, consequentemente, acaba por exigir da parte de Freud um aprimoramento técnico e conceitual no que diz respeito aos aspectos quantitativos.

Destacamos, em relação a esse período, a constituição de modelos propriamente psicanalíticos visando à compreensão do funcionamento anímico. E destacamos ao menos três obras em que a investigação freudiana, digna do momento de fundação das bases do campo psicanalítico, o conduz a um entrelaçamento profundo de suas teses aos fatos de ordem discursiva. São eles: $A$ interpretação de sonhos (1900/1996), Sobre a psicopatologia da vida cotidiana (1901a/1996) e Os chistes e sua relação com o inconsciente (1905a/1996). Como bem aponta Beividas (2006), principalmente com $A$ interpretação de sonhos, a Freud torna-se permitido circunscrever a técnica analítica na "imanência do discurso".

O que nos conduzirá igualmente à discussão dos aspectos epistemológicos ligados à metapsicologia é a introdução do conceito de "pulsão". Vejamos como Freud, já em 1905, apresenta o conceito em seus Três ensaios sobre a sexualidade: 
Por "pulsão" podemos entender, a princípio, apenas o representante psíquico de uma fonte endossomática de estimulação que flui continuamente, para diferenciá-la do "estímulo", que é produzido por excitações isoladas vindas de fora. Pulsão, portanto, é um dos conceitos da delimitação entre o anímico e o físico. A hipótese mais simples e mais indicada sobre a natureza da pulsão seria que, em si mesma, ela não possui qualidade alguma, devendo apenas ser considerada como uma medida da exigência de trabalho feita à vida anímica. $\mathrm{O}$ que distingue as pulsôes entre si e as dota de propriedades específicas é sua relação com suas fontes somáticas e seus alvos. A fonte da pulsão é um processo excitatório num órgão, e seu alvo imediato consiste na supressão desse estímulo orgânico (Freud, 1905b/1996, p. 159, grifo nosso).

Nesse pequeno excerto de texto, Freud expõe com precisão os componentes fundamentais da pulsão, como que antecipando, em quase uma década, a descrição feita em Os instintos e suas vicissitudes (Freud, 1915b/1996, p. 127): alvo (ou finalidade), fonte, objeto e pressão. E, na sequência do texto, a hipótese de "diferenças químicas" na constituição da diferença entre pulsões é lançada como que despretensiosamente, em caráter dito provisório, porém reforçando a importância da noção de excitação, de estímulo orgânico (Freud, 1905b, p. 159).

Importante notar que o surgimento do conceito de pulsão, mesmo em textos anteriores, dá-se num contexto de discussão marcadamente diferente daquele em que a quota de afeto e a quantidade começam a se fazer presentes no campo freudiano. Em outras palavras, é no registro da sexualidade que a pulsão adquire seu status conceitual. E, como tal, deve integrar duas cadeias de fenômenos: de um lado, a da excitação como representante das estimulações do corpo biológico, de outro, a dos derivados da elaboração psíquica. Isso porque, antes de tudo, sua configuração epistemológica visa a dar conta justamente da passagem da excitação para o interior do aparelho psíquico, ou seja, dos "representantes psíquicos". Esses representantes não devem ser lidos como uma representação qualquer, como referentes a não importa qual estímulo do mundo exterior, aos quais Freud marca nitidamente a diferença, mas sim como elementos pertencentes ao psiquismo (com todas as características inerentes a tal registro), mesmo que derivados, originados em sua fonte corporal.

\section{É nesse sentido que a pulsão começa a ter seu papel delineado, como bem aponta} Birman (1993), como um "ser-da-passagem", na transição "mítica" entre o somático e o psíquico, em que a "energia corporal" irá adquirir "materialidade semântica" (Birman, 1993, p. 19). Inversamente ao que possa parecer à primeira vista, o adjetivo mítico desempenha aqui um papel crucial, pois permite que seja assinalada uma espécie de "descontinuidade" entre o somático e o psíquico, ao menos no que poderia ser tido como uma suposta causalidade direta. Caso contrário, teríamos de ler a noção de pulsão como móvel de determinações de 
cunho somático e orgânico no psiquismo, em vez de, como destaca Birman, sua inscrição no universo da representação (Birman, 1993, p. 110). Essa descontinuidade seria semelhante, por exemplo, à ruptura metodológica que Lazzarini e Viana destacam quanto ao campo da biologia no que concerne ao entendimento de um "corpo biológico" e um corpo propriamente "psicanalítico" (Lazzarini \& Viana, 2006, p. 242). Trata-se aqui, pois, não da especificação de um vetor de determinação (dos estímulos orgânicos na formação dos representantes psíquicos), mas sim de estabelecer, em primeiro plano, a "medida de trabalho" a ser exercida pelo psíquico (por elaboração e associação) dos estímulos endógenos. Em outras palavras, ao psiquismo é exigido um trabalho de "semiotização", de produção de discurso (modo atual de entender os "representantes"), com base no material que lhe acomete. ${ }^{3} \mathrm{E}$ não é por menos que a sexualidade tenha aberto a possibilidade de tal tipo de compreensão, pois as práticas sexuais engendram em seu cerne noções como as de interesse, valor, prazer, desejo (noçôes das quais o ser humano não pode abrir mão para o seu exercício).

A hipótese de um substrato bioquímico para as pulsões não chega a ser sustentada por Freud definitivamente, estando muito mais próximo, digamos, de suas esperanças quanto às possibilidades de avanços futuros por parte da ciência. É nesse sentido que podemos encontrar, ao fim da obra Além do princípio de prazer Freud (1920/1996), uma longa conjectura a respeito. Nela, nos revela que "as deficiências de nossa posição provavelmente se desvaneceriam se nos achássemos em posição de substituir os termos psicológicos por expressôes fisiológicas ou quimicas" (Freud, 1920, p. 70). Mesmo apontando o caráter figurativo desse tipo de linguagem, ressalta a segurança que ela traz consigo além da simplicidade em seu uso, ou seja, características de uma ciência mais bem-acabada. O fechamento dessa passagem, diríamos elogiosa quanto aos princípios biológicos, dá-se na seguinte forma:

A biologia é verdadeiramente uma terra de possibilidades ilimitadas. Podemos esperar que ela nos forneça as informaçôes mais surpreendentes, e não podemos imaginar que respostas nos dará, dentro de poucas dezenas de anos, às questōes que lhe formulamos (Freud, 1920, p. 70, grifos do autor).

Embora Freud tenha sublinhado a proximidade com que a Biologia seria capaz de dar-nos respostas, não há como deixar de perceber aí o reconhecimento

\footnotetext{
3 Convém salientar o modo como o termo "semiótica" (e, por consequência, o ato de semiotização) é aqui compreendido. Segundo o Dicionário de Semiótica (Greimas \& Courtés, 2008), que serve de parâmetro para o ramo teórico que embasa este trabalho e que se inicia com Saussure, passando pela glossemática de Hjelmslev, até a semiótica modal, de Greimas, e a tensiva, representada por Fontanille e Zilberberg, devemos entender o termo semiótica sob as seguintes linhas: "Pondo-nos do lado da tradição de L. Hjelmslev, que foi o primeiro a propor uma teoria semiótica coerente, podemos aceitar a definição que ele oferece da semiótica: ele a considera uma hierarquia (isto é, como uma rede de relações hierarquicamente organizada) dotada de um duplo modo de existência, a paradigmática e a sintagmática (apreensível, portanto, como sistema ou como processo semiótico), e provida de pelo menos dois planos de articulação - expressão e conteúdo -, cuja reunião constitui a semiose" (Greimas \& Courtés, 2008). Importante, ainda, destacar que tal campo teórico se propõe como uma forma de oposição a linguísticas realistas e referencialistas que implicam à linguagem o mero papel de representação da realidade externa ou como ferramenta de comunicação de fatos externos a ela.
} 
de limites epistemológicos para com o campo psicanalítico, até mesmo pela confissão da impossibilidade de concretizar a esperança na substituição das expressões psicológicas pelas químicas ou fisiológicas. $\mathrm{Ou}$ ainda, como pode ser visto no texto de 1914 sobre o narcisismo (Freud, 2014/1996), a criação do campo psicanalítico deve-se, em certo sentido, ao movimento contrário de substituição de "substâncias químicas especiais por forças psíquicas especiais", o que deixa em aberto a questão de uma possível "subestrutura orgânica", porém caracteriza a noção de força como fenômeno psíquico, consequentemente, de uma psicanálise não naturalista ou reducionista (Freud, 1914, p. 86).

A temática da pulsão é, provavelmente, uma das mais complexas do campo psicanalítico e, indubitavelmente, permite uma série de abordagens diferentes, porém não aprofundaremos nesse tema. Como temos apontado, à abordagem quantitativa não somente do afeto, mas, de maneira geral, dos conceitos ligados ao ponto de vista econômico, proliferam intenções de substancialização de seus conceitos. Vejamos, como exemplo, que tal procedimento é igualmente dedicado ao conceito de pulsão. Segundo Hanns:

A Força Impelente e motivadora (o Trieb) brotará no indivíduo como fenômeno somático-energético. É descrita por Freud como: a) processo fisiológico que envolve neurônios, nervos, fontes pulsionais situadas em glândulas, etc. e b) como processo energético-econômico onde está em jogo o acúmulo de energia, a circulação e a descarga (Hanns, 1999, p. 32, grifo do autor).

Poderíamos dizer que, da forma como o autor apresenta o conceito, praticamente não há passagem para o registro do psiquismo. A essência da pulsão aqui entendida como fenômeno somático, energético, fisiológico, neuronal, nervoso, glandular, energético e, finalmente, econômico, reutilizando somente os termos empregados nesse pequeno parágrafo com tonalidade de postulado, não deixa margens para versões que autorizem igualmente a pertinência do outro e da linguagem. Porém o recurso ao quantitativo e, ou, à sua hipotética localização em substâncias de qualquer ordem (bioquímica, orgânica, neurofisiológica, entre outras) não são as únicas possibilidades ao se abordar o tema do afeto.

\section{ABORDAGEM METAFÓRICA DO AFETO}

Da mesma forma, há outra abordagem possível ao conceito de afeto, a qual, por meio de tentativas, declaradas ou implícitas, transfere o problema a uma espécie de metaforização de seus fundamentos. Dito de outra forma, a declaração e a defesa de um caráter metafórico como alicerce do ponto de vista econômico e dos conceitos a ele ligados permitiriam assentar tais leituras como alternativa a determinações de substratos materiais. Porém esse tipo de atitude subtrai o 
hipotético fundamento objetivo sem propor novas conjecturas em troca. É nesse sentido que Widlöcher (1986) critica determinadas formas de conceituar a pulsão, nas quais ela é "sempre outra coisa, menos aquilo que é denunciado pela crítica” (Widlöcher, 1986, p. 49). A abordagem metafórica consiste na crítica ao aspecto quantitativo sem discuti-lo, apenas tornando-o uma miragem inalcançável, em torno da qual a teoria continuaria a girar.

\section{OBSTÁCULOS EPISTEMOLÓGICOS}

Antes de adentrarmos no exame de hipóteses para uma abordagem propriamente discursiva do afeto, passamos rapidamente ao estudo dos impasses epistemológicos que poderiam colocar em risco o diálogo, acerca do tema, entre psicanálise e teorias da linguagem. Entre eles, foi possível destacar ao menos três, todos de extrema importância. $\mathrm{O}$ primeiro não poderia ser outro senão a perspectiva aberta pela abordagem quantitativa do afeto, de redução dos fenômenos afetivos (e demais vinculados à linguagem) a fatores determinados pelo substrato energético. Visto que as leituras da teoria psicanalítica propõem definições do afeto como quantidades de cunho energético ou processos a ela ligados, e, portanto, próximas a modelos organicistas e naturalistas, a posição quanto à linguagem se torna paradoxal. Isso porque dificilmente seria possível conjugar uma concepção de afeto apoiada em influxos energéticos com teorias que preconizam a imanência da linguagem, tais como a glossemática de Hjelmslev e as semióticas tensivas e modais, justamente as quais propomos uma aproximação possível.

Igualmente apontamos a posição, por vezes demissionária, da parte do campo lacaniano em relação à linguagem, de maneira geral, e aos conceitos de signo, sentido e significação, de maneira específica, como mais uma dificuldade para uma concepção discursiva do afeto em psicanálise. Tomado como unidade fechada, limitada e, portanto, limitante, o signo saussuriano é recorrentemente expresso por psicanalistas como um empecilho na formulação de abordagens discursivas e, pior, como referência ingênua, ultrapassada. Que Lacan (19721973/1985), numa passagem dedicada a Jakobson, no seminário de 1972-1973, tenha marcado distância entre a "linguística" e sua "linguisteria" (p. 24), a fim de deixar a ele reservado seu domínio, e ainda que tenha declarado nesse mesmo momento que sua tese do "inconsciente estruturado como uma linguagem" não pertence ao "campo da linguística" (p. 25), tais proposições não devem, a nosso ver, serem consideradas como impossibilidade de diálogo. Ao contrário, julgamos que o diálogo com as teorias da linguagem foi prematuramente interrompido sem que pudesse ser extraído dele todos os frutos que o encaminhamento inicial de Lacan notadamente indicava. ${ }^{4}$

\footnotetext{
4 Para um exame mais aprofundado do tema, propomos a leitura do artigo Psicanálise e linguística: uma relação "mal-começada", de um dos autores deste trabalho (Beividas \& Lopes, 2004).
} 
Por fim, outro ponto se refere aos impasses relacionados à concepção psicanalítica de real. A progressiva sensibilização do espírito freudiano para com a linguagem permitiu uma abertura epistemológica que aproximou a psicanálise de matrizes discursivas que tendem a fundamentarem-se em concepçóes imanentes de linguagem. A concepção de afeto, por sua vez, estaria justamente na encruzilhada entre duas diferentes possibilidades de abordagem do real: de um lado, a tendência realista inerente ao aspecto quantitativo e os projetos naturalistas e organicistas; de outro, a perspectiva de integrar conjecturas imanentistas com base num entendimento amplo dos processos de linguagem.

Por ora, nosso objetivo será o de delimitar bases discursivas para o afeto no interior da psicanálise. Assim, passaremos ao exame dos elementos que comporão o diálogo com as teorias da linguagem.

\section{BASES FREUDIANAS PARA UMA ABORDAGEM DISCURSIVA DO AFETO}

A abertura proporcionada por Freud à consideração da linguagem no campo psicanalítico vai além da introdução da fala como simples meio terapêutico. A talking cure (cura pela fala), como fora batizado o novo método por uma de suas pacientes, aponta para o caráter fundamental da linguagem tanto na eliminação dos sintomas como em sua própria formação. Se acompanharmos passo a passo a constituição do método psicanalítico, veremos que sua importância está arraigada na própria composição do aparelho psíquico. Como bem aponta Garcia-Roza (1991), desde $A$ interpretação das afasias Freud (1891/2003), ${ }^{5}$ começa a conquista de um território de linguagem (p. 37). Segundo Garcia-Roza: "A verdade é que o aparelho de linguagem produzido por Freud transbordou os limites estritos de um aparelho de linguagem e constitui-se como o primeiro modelo freudiano de aparelho psíquico" (Garcia-Roza, 1991, p. 68). Mesmo apontando na sequência que, naquele momento, não havia nada conclusivo para retirar de tal aparelho a sua caracterização como modelo neurológico, Garcia-Roza assinala o gradual "transbordamento" da linguagem, a ampliação de suas fronteiras, o extravasamento do qual a teoria psicanalítica é fruto. Os méritos das hipóteses centrais ao aparelho de linguagem das afasias são tais que, mais de 20 anos após sua aparição, vemos o resgate da distinção então definida entre "representação palavra" e "representação coisa" figurar novamente, em papel de destaque, no artigo metapsicológico sobre $O$ inconsciente (Freud, 1915a/1996).

Mesmo que se objete que a obra sobre as afasias trate de modelos neurocientíficos (mais especificamente da crítica ao localizacionismo de Meynert e Wernicke em 
prol de um funcionalismo à maneira de Hughlings Jackson) e que seja possível abordar o texto como introdução às neurociências, seria de fato despropositado submeter a teoria psicanalítica como um todo sob a influência de tal leitura. Até porque, e é esse ponto ao qual encaminhávamos nossa análise, mesmo que Freud tenha iniciado seu percurso no interior da discussão neurocientífica, ela acaba sendo, por fim, orientada para um longo e profícuo exame da linguagem que perdurará na teoria psicanalítica, e não o contrário. É a linguagem, pois, que vai gradativamente assumir a cena psicanalítica, em detrimento tanto da neuroanatomia quanto do funcionalismo neurocientífico. É deste modo que Birman (1993) nos apresenta a questão:

Pelo contrário, Freud rompeu com a psicologia, a psicopatologia e a neurologia do final do século XIX, justamente ao construir uma concepção do psiquismo fundada na linguagem. O "estudo crítico" sobre as afasias pode ser considerado legitimamente como o texto inaugural do saber psicanalítico, pois nele Freud concebe o psiquismo pelo modelo da linguagem, como um aparelho de linguagem. Aparelho de linguagem é o momento originário na construção do conceito freudiano de aparelho psíquico, na genealogia do discurso psicanalítico (p. 35, grifos nossos).

As leituras propostas por Garcia-Roza e Birman têm como ponto em comum ressaltar o texto sobre $A$ interpretação das afasias como origem da noção, diretiva quanto os rumos tomados pela história do movimento psicanalítico, de um aparelho psíquico fundamentado na linguagem. Tal atitude é francamente oposta a abordagens do afeto que o delimitariam em termos estritamente quantitativos ou meramente como metáforas das quantidades, na mesma medida em que constitui a base do que pode vir a ser uma abordagem discursiva do afeto. Ressaltar a centralidade da linguagem nos primórdios da obra freudiana, tanto na formação de sua escuta quanto na formulação de suas hipóteses teóricas, é, simultaneamente, delinear e priorizar as bases necessárias para o diálogo com teorias imanentes da linguagem, caso da glossemática de Hjelmslev (1966) e da semiótica tensiva, ou seja, teorias que se opõem a projetos teóricos no campo das linguísticas que consideram a linguagem a partir da noção realista de referente. $\mathrm{Na}$ contramão das reduções referencialistas, a glossemática e a semiótica tensiva caminham no sentido de delimitar o campo da linguagem como um conjunto de estruturações e hierarquias de diferenças que se estendem no plano do conteúdo e da expressão.

Essa postura referencialista é igualmente contrária aquela adotada por autores que veem no aparelho de linguagem das Afasias o modelo inicial do qual se originam, por desenvolvimentos ou diferenciações, as representaçóes subsequentes de aparelho psíquico na obra freudiana, sendo que tal postura 
não consiste em negar as relações existentes entre o modelo das afasias e noções neurocientíficas da época. Tal ressalva tem sua importância em função da série de trabalhos publicados, que visam a fazer desses pontos de proximidade os motivos para uma ligação de origem inexorável. Trata-se, enfim, de uma abertura à primordialidade da linguagem, ainda não alcançada plenamente pela teoria e técnica psicanalítica, porém repetidamente acenada.

Ao mesmo tempo, vemos Freud alinhar-se aos pressupostos essenciais à Linguística de Saussure ao situar a palavra como um objeto sincrético, constituído de "elementos acústicos, visuais e cinestésicos" (Freud, 1891, p. 42), muito embora hoje possa haver restriçōes quanto à hipótese de ver na palavra a unidade básica de função da linguagem. Entretanto tal questão, espécie de acerto no foco, parece-nos irrelevante diante da originalidade da suposição (anterior à boa parte dos desenvolvimentos da Linguística moderna) e, sobretudo, às consequências epistemológicas de seu dito. Isso porque, como a história da psicanálise parece nos indicar, o exame das funções da palavra não apenas persistiu no rol de noções cruciais à teoria como também sua delimitação como unidade no estudo psicológico demarca com primor o início da suposição dos fenômenos inconscientes por meio dos processos de linguagem, que culminará na oposição entre "representação-palavra" vs. "representação-objeto" (Freud, 1891, p. 46).

Assim, se há autores que forçam a leitura de um modelo neurocientífico incipiente presente no texto sobre as afasias, de nossa parte, fazemos a aposta de que há nele igualmente subsídios para a consideração de um "modelo semiótico", tão precoce quanto fascinante. Há que se levar em conta que a atenção de Freud nas afasias recai numa temática diretamente implicada na ordem de eventos própria à linguagem: a facilidade de desligamento entre a representação-palavra e a representação-objeto, o que, para Freud, destaca o caráter "puramente funcional de todo o aparelho da linguagem" (Freud, 1891, p. 51). A questão crucial aqui exposta é justamente a de que a visão freudiana sobre as afasias acaba por levá-lo à pressuposição da independência do aparelho de linguagem em relação à realidade exterior, posto que ao aparelho se torna possível tanto a ligação quanto o desligamento. A nosso ver, aqui está o gérmen do surgimento das teses principais tanto do texto Além do princípio do prazer (Freud, 1920) (a "ligação" anterior ao nivelamento das tensões) como também dos conceitos de "condensação" e "deslocamento" (posteriormente redefinidos por Lacan como "metáfora e metonímia", respectivamente). Esse delineamento acaba se tornando mais importante que a relação de Freud sobre "dependente concomitante" entre o psíquico e o seu processo paralelo, o fisiológico (Freud, 1891, pp. 3031), pois, nele, à linguagem é dada a faculdade de inverter, reverter e mesmo desfazer o que o substrato cerebral e perceptivo tratou de unir. Como não ver 
nesse procedimento, mais do que uma vinculação a tradições neurocientíficas, o nascimento in loco do inconsciente freudiano?

Se retomarmos os principais textos do início da teoria e tratamento psicanalítico propriamente dito, veremos que tal alteração de foco é essencial no que diz respeito à originalidade do pensamento freudiano. É nesse sentido que Lionço (2008), ao buscar fazer um recenseamento das teses psicanalíticas a respeito da relação entre corpo e psiquismo, indica-nos um montante de leituras que ressalta justamente a subversão do corpo pelo psiquismo, certamente, pela linguagem. Conforme podemos acompanhar nas palavras da autora:

Apesar de diferir em sua perspectiva em relação aos neurologistas da época, não se pode afirmar que Freud abandona a questão do corpo em favor do psíquico. O que Freud pôde perceber é que na histeria o corpo orgânico em sua funcionalidade é subvertido. Não se trata de um abandono da consideração do corpo, mas da postulação de um novo estatuto para o corpo, que deixa de restringi-lo à sua condição somática (Lionço, 2008, p. 118).

Do corpo "objeto biológico" ao corpo "atravessado pela linguagem", de tal modo poderíamos resumir o percurso acima citado. E não por acaso as principais vias de constituição das teses sobre o inconsciente se deram, primeiramente, com a escuta das pacientes histéricas e a atenção ao desacreditado fenômeno do sonho, nas quais a linguagem faz sentir de forma pungente a sua intensidade. Logo, a direção do movimento de pensamento freudiano que nos é legado trata de orientar a questão da oposição estanque entre corpo e alma para abordar, mediante os processos discursivos, a tomada do corpo pela linguagem.

\section{CONSIDERAÇÕES FINAIS}

Como nos foi possível apontar ao longo do artigo, se a obra freudiana oferece subsídios para uma discussão de seus pressupostos por vias bioquantitativas, por outro lado, a aproximação para com os temas clínicos rapidamente reinsere o tema do afeto no âmbito das operações e transformações na ordem do discurso, seja na constituição dos fatos psíquicos, seja na formação dos sintomas. As experiências e atos de pensamento afetivos, indubitavelmente, deslocam o enfoque do registro concernente às supostas reduções energéticas e sua determinação quantitativa dos fenômenos em questão para colocá-lo no seio das hipóteses acerca do trabalho psíquico de elaboração do material que lhe acomete. Trata-se, pois, da tarefa de composição, exercida pelo aparelho, de fazer com que as apresentações residuais (ou seja, formas rústicas de apreensão perceptiva) tornem-se figuras mais complexas de representação. Essa maneira de 
alinhar o processo de formação do sintoma com uma abordagem discursiva do afeto é a tal ponto recorrente na teoria freudiana que podemos encontrá-la em diversos textos. Vejamos uma passagem de Inibiçôes, sintoma e anguistia, em que o afeto é delimitado nesses mesmos termos:

A angústia não é criada novamente na repressão; é reproduzida como um estado afetivo de conformidade com uma imagem mnêmica já existente. Se formos adiante e indagarmos da origem dessa angústia - e dos afetos em geral - estaremos deixando o domínio da psicologia pura e penetrando na fronteira da fisiologia. Os estados afetivos têm-se incorporado na mente como precipitados de experiências traumáticas primevas, e quando ocorre uma situação semelhante são revividos como símbolos mnêmicos (Freud, 1926/1996, p. 97).

Importante notar que a ressalva freudiana quanto à participação, ao lado do domínio psicológico, da ordem de fenômenos biofisiológica na formação dos afetos em geral (sendo a angústia colocada sob o mesmo mote), rapidamente dá lugar a uma definição processual do afeto, ressaltando novamente a transição dos "resíduos mnêmicos", então citados como precipitados traumatizantes (a sua configuração como "símbolo"). Por mais que esse termo possa ter consequências epistemológicas complexas, e, em razão disso, tenha dado origem a uma série de mal-entendidos e extrapolações teóricas, das quais Lacan foi o maior crítico, a discussão então retomada por Freud é, uma vez mais, a do afeto como processo de inserção psíquica da intensidade dos fenômenos.

O aspecto de "trauma", unicamente compreensível dentro de uma dinâmica de espessura temporal e de maturação discursiva inerente à concepção do "sódepois" (o Nachträglich freudiano), aponta, nessa citação, a incidência sobre o aparelho psíquico não de uma quantidade qualquer, de uma espécie de força indeterminada, mas sim de um abalo que depende do sentido e de sua inclusão na história pessoal, em seu universo discursivo, para somente então se constituir. Simultaneamente a esse traço constitutivo, a retomada da experiência afetiva torna-se, portanto, menos suscetível a ser implicada nos processos de "descarga" do que propriamente no regime da sensibilidade aos símbolos, à memória, ao sentido e, sobretudo, ao arranjo histórico que a eles foi possível no registro inconsciente.

O resultado de tal abordagem do afeto é o que, nas palavras de Schneider (1993) deve ser compreendido como a não oposição entre afeto e expressão verbal na transmutação do orgânico para a ordem propriamente afetiva, pois, de acordo com a autora, "A expressão afetiva participaria, por si mesma, no que constitui a essência da linguagem" (Schneider, 1993, p. 80). Segundo o enfoque que procuramos defender em nossos trabalhos, a transmutação acima 
citada poderia ser mais bem compreendida no diálogo entre a teoria lacaniana e a semiótica tensiva. Quanto ao segundo ponto em destaque, que é o da participação do afeto na constituição da linguagem, pretendemos tomar a questão por outro enfoque. Para evitar suposiçóes de prevalência (o afeto formando a linguagem ou a linguagem dando vida ao afeto), apostamos na abordagem discursiva como interdefinição imanente, ou seja, situar o ponto de vista econômico pelo enfoque tensivo sobre o valor na mesma medida em que os processos de significação encontram aí sua precondição. Dito em outras palavras, o afeto pode ser compreendido como participante fundamental da ordem de linguagem, não como um elemento a ela exterior e oposto, mas sim numa discussão rigorosa e imanente sobre a forma essencial da linguagem por meio da rediscussão de seu aspecto de intensidade e valor. Dessa forma, procuramos evitar a atitude definida criticamente por Hoffmann como cientificista, calcada no "desconhecimento do lugar e da função da linguagem na relação do homem com o real" (Hoffmann, 2007, p. 44).

Tido assim como um fio condutor na análise dos aspectos ligados à intensidade do discurso, o conceito de afeto exerce, nas teses freudianas sobre a economia psíquica, o encargo de garantia epistemológica. Sabemos estar progredindo na via correta, desde o evento freudiano que nos concedeu as bases da escuta analítica, na justa medida em que os afetos começam a aflorar. Da mesma forma, só podemos averiguar se uma interpretação toca no coração da verdade por meio de seus fenômenos afetivos decorrentes.

Trata-se, então, da descarga de uma energia? Da expressão de uma descarga? $\mathrm{Ou}$, visto pelo ângulo oposto, da resultante do complexo de significantes e intensidades, de significações e tensões que fazem dos fenômenos afetivos testemunhas do caráter absolutamente pregnante da linguagem nos fatos psíquicos? Visto que engaja o sujeito numa isotopia, num encadeamento discursivo em tudo o que ele implica de intensidade e sentido, o afeto nos provê uma nova visada do procedimento terapêutico que nos foi legado por Freud e, possível somente a partir da adoção da função da fala como via privilegiada de acesso ao inconsciente.

Reafirmamos, assim, nossa aposta na possibilidade de uma abordagem discursiva para o conceito de afeto não como a defesa de mais uma ordem de fatos a ser somada à da representação, mas sim como fundamento inerente à constituição dos processos psíquicos conscientes e inconscientes. É desse modo que Freud insere o conceito de afeto no debate maior que se estende, desde o Projeto, a respeito das qualidades no acontecer psíquico. Sobre o tema, vejamos o seguinte excerto de $A$ interpretação dos sonhos: 
Os processos de pensamento, em si próprios, carecem de qualidade, exceto pelas excitações prazerosas e desprazerosas que os acompanham e que, em vista de seu possível efeito perturbador sobre o pensamento, têm de ser mantidas dentro de limites. Para que os processos de pensamento possam adquirir qualidades, eles se associam, nos seres humanos, com lembranças verbais, cujos resíduos de qualidade são suficientes para atrair para si a atenção da consciência e para adotar o processo de pensar de um novo investimento móvel oriundo da consciência (Freud, 1900, pp. 641-642).

Como bem aponta David-Ménard (2000), mais do que as metáforas ou pressuposições energéticas, o ensino freudiano a respeito do inconsciente e seus processos tem como base a importância delegada ao prazer. O que a passagem acima exposta nos coloca de mais importante é, precisamente, que tanto o substrato para os investimentos móveis (ou seja, sua quantidade inserida no quadro do prazer) quanto os fatos elementares do pensamento humano (sua qualidade) devem manter relação intrínseca com os componentes rudimentares da linguagem. Nesse sentido, buscar a delimitação de uma abordagem discursiva para o afeto torna-se plenamente admissível, para não dizer desejável.

Para concluir, lembramos o exame feito por Dör (1991) sobre o tema do sonho, fazendo nossas as suas palavras:

Encontramos, assim, uma das prescrições freudianas mais fundamentais, que aparece na entrada do edifício analítico: "o sonho é a via real que leva ao inconsciente". Mas esta prescrição só tira sua eficácia na medida em que o sujeito é encaminhado a sustentar um "discurso" com referência ao seu sonho. É o discurso que é a via real. Sem ele, não haveria decodificação possível para a passagem-ao-ato do inconsciente (p. 20, grifo do autor).

Se o discurso é a via real aberta por Freud, condição essencial para a descoberta do inconsciente e de seus processos, certamente não haveria de ser diferente quanto ao afeto. 


\section{REFERÊNCIAS}

Andrade, V. M. (2003). Um diálogo entre a psicanálise e a neurociência. São Paulo: Casa do Psicólogo.

Assoun, P.-L. (1996). Metapsicologia freudiana: uma introdução. Rio de Janeiro: Jorge Zahar.

Barros, C. P. (1998a). Conceitos termodinâmicos e evolucionistas na estrutura formal da metapsicologia de Freud. Cadernos do Tempo Psicanalítico, 3, 13-51.

Barros, C. P. (1998b). Contribuição à controvérsia sobre o "ponto de vista econômico". Cadernos do Tempo Psicanalítico, 3, 53-89.

Beividas, W. (2006). Sémiotique du discours onirique: le rêve de Freud. Révue Internationale Langage \& Inconscient, 2, 9-29.

Beividas, W. \& Lopes, M. (2004). Psicanálise e linguística: uma relação "mal começada”. Pulsional revista de psicanálise, 177(16), 28-42.

Birman, J. (1993). Ensaios de teoria psicanalítica: metapsicologia, pulsão, linguagem, inconsciente e sexualidade (Vol. 1). Rio de Janeiro: Jorge Zahar.

Birman, J. (2007). Mal-estar na atualidade: a psicanálise e as novas formas de subjetivação. Rio de Janeiro: Civilização Brasileira.

Caropreso, F. \& Simanke, R. T. (2006). Compulsão à repetição: um retorno às origens da metapsicologia freudiana. Agora, 9(2), 207-224.

Caropreso, F. \& Simanke, R. T. (2008). Uma reconstituição da estratégia freudiana para a justificação do inconsciente. Ágora, 11(1), 31-51.

Changeux, J. P. (1998). L’homme neuronal. Paris: Hachette Pluriel.

Damasio, A. (2000). L'erreur de Descartes. Paris: Odile Jacob.

David-Ménard, M. (2000). Tout leplaisir estpour moi. Paris: Hachette Littératures.

Dennett, D. (1997). Tipos de mentes. Rio de Janeiro: Rocco.

Dör, J. (1991). Estruturas e clínica psicanalitica. Rio de Janeiro: Taurus-Timbre.

Freud, S. (1891). A interpretação das afasias. Lisboa: Edições 70, 2003. (Publicado originalmente em 1891). 
Freud, S. (1893a). Algumas considerações para um estudo comparativo das paralisias motoras orgânicas e histéricas. In J. Salomão (Trad.), Edição standard das obras psicológicas completas de Sigmund Freud (Vol. 1, pp. 199-216). Rio de Janeiro: Imago, 1996. (Publicado originalmente em 1893).

Freud, S. (1893b). Estudos sobre histeria. In J. Salomão (Trad.), Edição standard das obras psicológicas completas de Sigmund Freud (Vol. 2, pp. 13-329). Rio de Janeiro: Imago, 1996. (Publicado originalmente em 1893).

Freud, S. (1895). Projeto para uma psicologia científica. In J. Salomão (Trad.), Edição standard das obras psicológicas completas de Sigmund Freud (Vol. 1, pp. 335-469). Rio de Janeiro: Imago, 1996. (Publicado originalmente em 1895).

Freud, S. (1900). A interpretação dos sonhos. In J. Salomão (Trad.), Edição standard das obras psicológicas completas de Sigmund Freud (Vol. 4-5, pp. 11650). Rio de Janeiro: Imago, 1996. (Publicado originalmente em 1900).

Freud, S. (1901a). Sobre a psicopatologia da vida cotidiana. In J. Salomão (Trad.), Edição standard das obras psicológicas completas de Sigmund Freud (Vol. 6, pp. 13-291). Rio de Janeiro: Imago, 1996. (Publicado originalmente em 1901).

Freud, S. (1901b). Sobre os sonhos. In J. Salomão (Trad.), Edição standard das obras psicológicas completas de Sigmund Freud (Vol. 5, pp. 653-700). Rio de Janeiro: Imago, 1996. (Publicado originalmente em 1901).

Freud, S. (1905a). Os chistes e sua relação com o inconsciente. In J. Salomão (Trad.), Edição standard das obras psicológicas completas de Sigmund Freud (Vol. 8, pp. 11-232). Rio de Janeiro: Imago, 1996. (Publicado originalmente em 1905).

Freud, S. (1905b). Três ensaios sobre a teoria da sexualidade. In J. Salomão (Trad.), Edição standard das obras psicológicas completas de Sigmund Freud (Vol. 7, pp. 119-232). Rio de Janeiro: Imago, 1996. (Publicado originalmente em 1905).

Freud, S. (1906). Minhas teses sobre o papel da sexualidade na etiologia das neuroses. In J. Salomão (Trad.), Edição standard das obras psicológicas completas de Sigmund Freud (Vol. 7, pp. 255-265). Rio de Janeiro: Imago, 1996. (Publicado originalmente em 1906).

Freud, S. (1914). Sobre o narcisismo: uma introdução. In J. Salomão (Trad.), Edição standard das obras psicológicas completas de Sigmund Freud (Vol. 14, pp. 77-108). Rio de Janeiro: Imago, 1996. (Publicado originalmente em 1914). 
Freud, S. (1915a). O inconsciente. In J. Salomão (Trad.), Edição standard das obras psicológicas completas de Sigmund Freud (Vol. 14, pp. 165-222). Rio de Janeiro: Imago, 1996. (Publicado originalmente em 1915).

Freud, S. (1915b). Os instintos e suas vicissitudes. In J. Salomão (Trad.), Edição standard das obras psicológicas completas de Sigmund Freud (Vol. 14, pp. 117144). Rio de Janeiro: Imago, 1996. (Publicado originalmente em 1915).

Freud, S. (1920). Além do princípio do prazer. In J. Salomão (Trad.), Edição standard das obras psicológicas completas de Sigmund Freud (Vol. 18, pp. 13-75). Rio de Janeiro: Imago, 1996. (Publicado originalmente em 1920).

Freud, S. (1923). Dois verbetes de enciclopédia. In J. Salomão (Trad.), Edição standard das obras psicológicas completas de Sigmund Freud (Vol. 18, pp. 251274). Rio de Janeiro: Imago, 1996. (Publicado originalmente em 1923).

Freud, S. (1925). Um estudo autobiográfico. In J. Salomão (Trad.), Edição standard das obras psicológicas completas de Sigmund Freud (Vol. 20, pp. 11-78). Rio de Janeiro: Imago, 1996. (Publicado originalmente em 1925).

Freud, S. (1926). Inibições, sintomas e ansiedade. In J. Salomão (Trad.), Edição standard das obras psicológicas completas de Sigmund Freud (Vol. 20, pp. 81171). Rio de Janeiro: Imago, 1996. (Publicado originalmente em 1926).

Gabbi Junior, O. F. (2003). Notas a projeto de uma psicologia. Rio de Janeiro: Imago.

Garcia-Roza, L. A. (1991). Introdução à metapsicologia freudiana. Rio de Janeiro: Jorge Zahar.

Gomes, G. (2005). O problema mente-cérebro em Freud. Piscologia: Teoria e Pesquisa, 21(2), 149-155.

Greimas, A. J. \& Courtés, J. (2008). Dicionário de semiótica. São Paulo: Contexto.

Grünbaum, A. (1993). La psychanalyse à l'épreuve. Paris: L'Éclat.

Grünbaum, A. (1998). Les fondements de la psychanalyse. Paris: Presses Universitaires de France.

Hanns, L. A. (1999). A teoria pulsional na clínica de Freud. Rio de Janeiro: Imago.

Hjelmslev, L. (1966). Le langage. Paris: Minuit. 
Hoffmann, C. (2007). Des cerveaux et des hommes: nouvelles recherches psychanalytiques. Ramonville Saint-Ange: Érès.

Changeux, J.-P., Churchland, P., Missa, J. N., Stengers, I., Engel, P., Dupuis, M. \& Gillet, G. (1991). Philosophie de l'esprit et sciences du cerveau: annales de L'institut de Philosophie de L'université de Bruxelles. Paris: Vrin.

Lacan, J. (1972-1973). Mais, ainda. In J. Lacan, J. A. Miller. O seminário: Livro 20. Rio de Janeiro: Jorge Zahar, 1985. (Publicado originalmente em 19721973).

Lazzarini, E. R. \& Viana, T. C. (2006). O corpo em psicanálise. Psicologia: Teoria e Pesquisa, 22(2), 241-250.

Lionço, T. (2008). Corpo somático e psiquismo na psicanálise: uma relação de tensionalidade. Agora, 11(1), 117-136.

Plastino, C. A. (2001). O primado da afetividade. Rio de Janeiro: RelumeDumará.

Rossi, J. C. (2005). A representação, o afeto e a defesa no projeto de uma psicologia (1895). Psicologia: Teoria e Pesquisa, 21(1), 93-97.

Roudinesco, E. (2000). Por que a psicanálise? Rio de Janeiro: Jorge Zahar.

Schneider. M. (1993). Afeto e linguagem nos primeiros escritos de Freud. São Paulo: Escuta.

Sulloway, F. (1998). Freud, biologiste de l'esprit. Paris: PUF.

Widlöcher, D. (1986). Métapsychologie du sens. Paris: PUF. 